\title{
Controle de Potência em Redes OCDMA Estrela de Múltiplo Acesso via Modelo de Verhulst
}

\author{
Moanir Stábile Filho, Fábio R. Durand, Fernando Ciriaco, Taufik Abrão
}

\begin{abstract}
Resumo-A utilização da técnica de acesso múltiplo por divisão de códigos (CDMA) em redes puramente ópticas foi proposta levando-se em consideração sua ampla largura de banda óptica. O CDMA óptico é uma técnica que permite a múltiplos usuários compartilharem simultaneamente o mesmo canal de fibra de modo assíncrono sem delay e sem a necessidade de gerenciamento de recursos (scheduling). No entanto, os níveis de interferência de múltiplo acesso (MAI) serão significativos nesses sistemas devido à natureza da detecção de potência incoerente. A redução desse efeito de interferência é crucial na melhoria de desempenho dos sistemas CDMA ópticos. Neste sentido, propõese a utilização de mecanismos de controle de potência, que garante a cada usuário uma quantidade mínima de potência necessária para um desempenho aceitável do sistema. No controle de potência centralizado é necessário que um nó central tenha informações sobre o ganho de todos os links. Já no controle de potência particionado (rede de acesso e rede de broadcast) verifica-se que os sinais ópticos após o acoplador estrela não contribuem na determinação da MAI e por conseguinte na potência ótima. Neste trabalho, é proposto o controle de potência para redes opticas particionadas a partir do modelo matemático de Verhulst, modelo inicialmente elaborado para descrever o crescimento populacional de espécies biológicas com restrição de espaço físico e de alimento. Com base na comparação dos resultados verificou-se que o modelo de Verhulst é adequado ao problema do controle de potência em redes CDMA ópticas particionadas.
\end{abstract}

Palavras-Chave-CDMA óptico, controle de potência centralizado, modelo de Verhulst.

Keywords-Optical CDMA, centralized power control, Verhulst equilibrium equation

\section{InTROduÇÃo E DESCRIÇÃo Do ProblemA}

Com o intuito de tornar mais útil o uso de toda a largura de banda disponível nas redes ópticas, estudos mostram que CDMA óptico oferece uma solução interessante para redes de múltiplo acesso. Muitas alternativas para aumentar a eficiência espectral das redes ópticas e otimizar a utilização de sua enorme largura de banda foram sugeridas, entre elas: acesso múltiplo por divisão de comprimento de onda (WDMA) utilizando multiplexadores add-drop reconfiguráveis, acesso múltiplo por divisão de tempo óptico (OTDMA) e acesso múltiplo por divisão de código óptico (OCDMA). Em um

Moanir Stábile Filho é estudante de mestrado, Departamento de Engenharia Elétrica da Universidade Estadual de Londrina, 86051-990, PR. moanir@gmail.com

F. R. Durand é Professor Adjunto do Departamento de Engenharia Elétrica da Universidade Norte do Paraná, Londrina, PR; fabio.durandeunopar.br

F. Ciriaco é estudante de doutorado da Escola Politécnica da Universidade de São Paulo, SP fciriaco@uel.br

Taufik Abrão é Professor Associado do Departamento de Engenharia Elétrica da Universidade Estadual de Londrina; taufik@uel.br www. uel.br/pessoal/taufik sistema OCDMA diferentes transmissores fazem o uso de códigos diferentes para espalhar seus dados, tanto no domínio do tempo como no domínio da frequência. Os códigos são cuidadosamente projetados para que muitos transmissores possam transmitir simultaneamente sem interferir um no outro, e o receptor pode selecionar o sinal transmitido desejado decodificando adequadamente o sinal recebido [1]. OCDMA permite acesso simultâneo à rede por múltiplos usuários e possui muitas vantagens, tais como, soft capacity, transmissão de pacotes robusta, atraso de pacotes desprezível e operação assíncrona [2]. Então, OCDMA é considerado como uma das principais tecnologias futuras para tráfego multimedia suportando vários níveis de QoS. Todos os sistemas OCDMA sofrem do problema de near-far onde os nós mais próximos tem suas potências muito mais superiores do que as potências dos nós mais distantes. Portanto, transmitir o controle de potência foi sugerido para as redes OCDMA para equalizar a potência recebida de todos os usuários resultando em um considerável ganho de capacidade, já que esse controle de potência se mostrou bastante eficiente nos sistemas sem-fio [3]. Para redes OCDMA com nível de QoS igual para todos os terminais e todos os nós localizados a uma mesma distância do acoplador estrela, o controle de potência pode ser desprezado. Devido ao aumento da demanda de vários níveis de QoS, assim como nós muito espalhados geograficamente, o controle de potência vai ser um ponto crítico em redes OCDMA. Implementando sistemas com vários níveis de QoS faz as redes ópticas muito mais eficientes devido a otimização dos recursos disponíveis [4].

A interferência de múltiplo acesso (MAI) pode ser bem elevada se comparado a sistemas CDMA sem-fio. O controle de potência suaviza o MAI, aumentando a performance e throughput da mesma forma que nos sistemas CDMA sem-fio. O controle de potência centralizado oferece ótima potência de transmissão distribuído entre os nós transmissores que tentam maximizar a relação portadora-interferência (CIR) desejada. No entanto, o controle de potência centralizado tem uma desvantagem, é necessário um nó central com informação sobre o ganho de todos os links.

Trabalhos anteriores considerando o problema do controle de potência em sistemas OCDMA estrela incluem [5], [4], [6], onde foram encontradas várias alternativa para a solução desse problema. Em [5] foi proposto o particionamento da rede estrela em duas: rede de acesso e rede de broadcast. Assim cada usuário poderia ser equipado com a informação do status dos outros nós, isso permite a distribuição de potência apropriada para suportar o balanceamento de potência. Já em [4] foi investigado o efeito da não-linearidade do fotodetector utilizando potência de transmissão ótimo em uma rede 
OCDMA. O controle de potência não-linear óptico foi resolvido por repetições de um algoritmo proposto que converge a um ponto único. E em [6], é utilizada Spectral Amplitude Coding (SAC), uma técnica muito eficiente para eliminação da MAI, que se mostrou também vantajosa para o controle de potência, sem deixar o decodificador mais complexo em relação ao decodificador sem controle de potência.

Neste trabalho é estudado uma forma de se fazer o controle de potência utilizando o modelo de Verhulst e comparando-o com os resultados obtidos com controle de potência centralizado e controle de potência particionado encontrados em [5].

\section{Modelo do Sistema}

Seja a rede de comunicação CDMA óptica com topologia estrela $K \times K$ da Fig. 1. Cada usuário possui dois links de fibra, um para transmissão e outro para recepção que podem ser conseguidos utilizando-se diferentes fibras ou diferentes comprimentos de onda. Para as fibras são considerados desprezíveis os coeficientes de dispersão e não-linearidade, somente a atenuação da fibra é levada em conta. Se as distâncias entre os nós e o acoplador estrela forem muito diferentes, como encontrado na prática, deverá ser considerado também o problema de near-far e algum tipo de controle de potência deverá ser aplicado para otimização do sistema.

Nesta análise [5], $\mathrm{Tx}_{i}$ é o transmissor e $\mathrm{Rx}_{i}$ é o receptor, Fig. 1. No transmissor, os dados de cada usuário são convertidos do domínio elétrico para o óptico com o uso de um diodo laser e então codificados opticamente utilizando uma linha de atraso óptico para produzir o sinal OCDMA temporal. As potências dos lasers foram chamadas de $P_{i}$ para $i=1,2$, $\ldots, K$. O sinal óptico codificado CDMA sofre atenuação ao longo do enlace do nó com o acoplador estrela e depois pelo próprio acoplador estrela após transmitir o sinal para todos os nós através das fibras receptoras, com isso consegue-se ter sempre o sinal e a interferência sobrepostos desejados no nó receptor. Esse sinal composto é então decodificado por um filtro óptico compatível com o código do usuário desejado. As perdas de potência na codificação e decodificação ópticas foram consideradas iguais, então são somadas às outras perdas da fibra. Para um comprimento de fibra óptica total $L_{i j}[\mathrm{~km}]$ do $j$-ésimo nó Tx ao $i$-ésimo nó $\mathrm{Rx}$, as potências de entrada e saída da rede são, [7]:

$$
P_{r}=a_{\text {estrela }} P_{t} \exp (-\alpha L),
$$

$$
a_{\text {estrela }}=10 \log _{10} K-\left(\log _{2} K\right) 10 \log _{10} \gamma
$$

onde

$P_{r}=$ potência recebida;

$P_{t}=$ potência transmitida;

$\alpha=\frac{a}{10 \log (e)}$;

$a=$ coeficiente de atenuação da fibra $[\mathrm{dB} / \mathrm{km}]$;

$a_{\text {estrela }}=$ atenuação do acoplador estrela $[\mathrm{dB}]$;

$\gamma=$ relação de perda excessiva.

$\mathrm{Na}$ rede da Fig. 1, assume-se que todos os nós da rede estão distribuídos uniformemente em uma área centralizada no acoplador estrela com raio de $L_{\min } \leq r \leq L_{\max }$. O comprimento total da fibra conectando o $i$-ésimo nó receptor

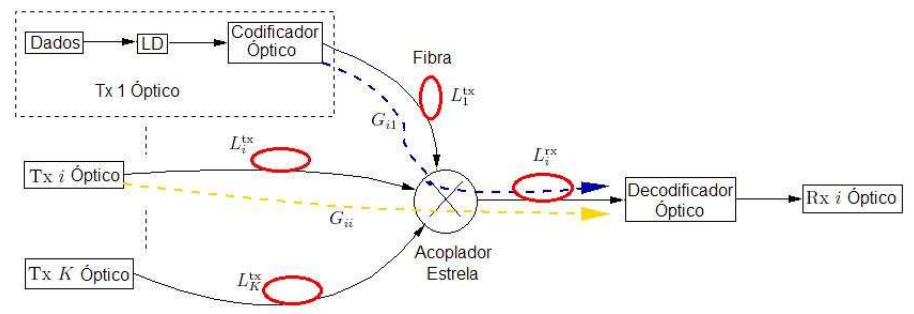

Fig. 1. Rede CDMA Óptica em Estrela.

ao j-ésimo nó transmissor através do acoplador estrela pode ser representado por

$$
L_{i j}=L_{j}^{\mathrm{tx}}+L_{i}^{\mathrm{rx}} ; \quad i, j=1,2, \ldots, K,
$$

sendo: $L_{j}^{\mathrm{tx}}$ o comprimento de fibra do nó transmissor até o acoplador, e $L_{i}^{\mathrm{rx}}$ o comprimento de fibra do nó receptor até o acoplador. Neste caso, denomina-se $\mathbf{G}$ a matriz de atenuação da fibra que conecta todos os pares transceptores, podendo ser determinada substituindo-se (3) em (1)

$$
\mathbf{G}=\left[\begin{array}{cccc}
G_{11} & G_{12} & \cdots & G_{1 K} \\
G_{21} & G_{22} & \cdots & G_{2 K} \\
\vdots & \vdots & \ddots & \vdots \\
G_{K 1} & G_{K 2} & \cdots & G_{K K}
\end{array}\right]
$$

sendo $G_{i j}$ o elemento da matriz que representa a atenuação entre o nó $j$ Tx e o nó $i$ Rx.

Os codificadores ópticos da Fig. 1 codificam os bits dos dados numa série de pulsos ópticos de alta taxa utilizando as regras do Prime Code. O Prime Code gerado consiste de um conjunto de blocos contendo um único pulso. Para qualquer número primo $q$ um código consiste de $q$ blocos de duração $q$ chips. Um conjunto de sequências de códigos de duração $N=q^{2}$ foi derivado em [8]. Quando os $K$ usuários estão transmitindo simultaneamente, a interferência total em um dado receptor consiste da superposição de $K-1$ funções de correlação cruzada distintas. Para essa classe de seqüências de espalhamento, a variância para as amplitudes da correlação cruzada é de $\sigma_{C C}^{2} \approx 0,29$, a qual resulta independente de $q$, [7].

Admitindo-se controle perfeito de potência para todos os usuários ópticos, a relação sinal-interferência média $(\overline{S I R})$ é simplesmente,

$$
\overline{S I R}=\frac{q^{2}}{\sigma_{C C}^{2}(K-1)}
$$

Adicionalmente, utilizando aproximação Gaussiana quando um grande número de usuários ópticos estão ativos, a probabilidade de erro de bit pode ser de aproximada por [9]:

$$
P_{E}=Q\left(\frac{\sqrt{\overline{S I R}}}{2}\right)
$$

\section{A. O Problema do Controle de Potência em Redes Ópticas}

O controle de potência óptico em uma rede é um problema de otimização. Denominando-se $\Gamma_{i}$ a razão entre a potência da portadora pela potência da interferência (CIR) desejada à 
entrada do decodificador de interesse, tendo em vista obter uma certa Qualidade de Serviço (QoS) associada à taxa de erro de bit (BER) máxima tolerada para o $i$-ésimo usuário, e definindo-se o vetor-coluna $K$-dimensional da potência óptico transmitida $\mathbf{P}=\left[P_{1}, P_{2}, \ldots, P_{K}\right]^{T}$, então o problema do controle de potência óptico centralizada consiste em encontrar o vetor de potência óptico $\mathbf{P}$ que minimiza a função custo [10]:

$$
J(\mathbf{P})=\mathbf{1}^{T} \mathbf{P}=\sum_{i=1}^{K} P_{i}
$$

sujeito às restrições:

$$
\begin{aligned}
\Gamma_{i} & =\frac{P_{i} G_{i i}}{\sum_{j=1 ; j \neq i}^{K} P_{j} G_{i j}+N_{i}} \geq \Gamma^{*} \\
& \leq P_{i} \leq P_{\max } \quad \forall i=1, \ldots, K
\end{aligned}
$$

onde

$\mathbf{1}^{T}=[1, \ldots, 1]$,

$K$ = número de usuários ativos na rede óptica,

$G_{i j}=$ atenuação da fibra entre o $j$-ésimo nó transmissor e o $i$-ésimo nó receptor,

$N_{i}=$ potência do ruído no nó receptor $i$,

$\Gamma^{*}=$ CIR mínima,

Utilizando notação matricial, (8) pode ser expressa,

$$
\left[\mathbf{I}-\Gamma^{*} \mathbf{H}\right] \mathbf{P} \geq \mathbf{u},
$$

sendo $\mathbf{I}=$ matriz identidade, $\mathbf{H}=$ matriz interferência normalizada, cujos elementos são definidos por:

$$
H_{i j}=\left\{\begin{aligned}
0, & i=j, \\
\frac{G_{i j}}{G_{i i}}, & i \neq j,
\end{aligned}\right.
$$

$\mathrm{e}$

$$
u_{i}=\frac{\Gamma^{*} N_{i}}{G_{i i}},
$$

em (12) tem-se a forma escalar do ruído. Resolvendo (10) substituindo a desigualdade por uma igualdade, obtém-se a solução do vetor potência ótimizada através da inversão de matriz:

$$
\mathbf{P}^{*}=\left[\mathbf{I}-\Gamma^{*} \mathbf{H}\right]^{-1} \mathbf{u}
$$

Tal vetor de potência óptico representa o caso de equilíbrio de potência no nó receptor, e é então a potência ótima exigida para alcançar a CIR desejada. Aumentando o valor da CIR resultaria em valores de potência óptica mais elevados que poderiam resultar maiores que a potência máxima permitida. Neste caso a solução seria fixar ou diminuir o valor da CIR desejada ou remover (desligar) alguns usuários da rede.

Ajustando a potência do ruído para zero e supondo equilíbrio perfeito da potência recebida em (8), pode-se considerar que a CIR máxima alcançável com limitada MAI é,

$$
\Gamma_{\max }=\frac{1}{K-1}
$$

Assim, a máxima CIR que pode ser alcançada na rede é limitada ao número de nós (independendo do comprimento da fibra), o qual é similar ao caso de uma única célula em um

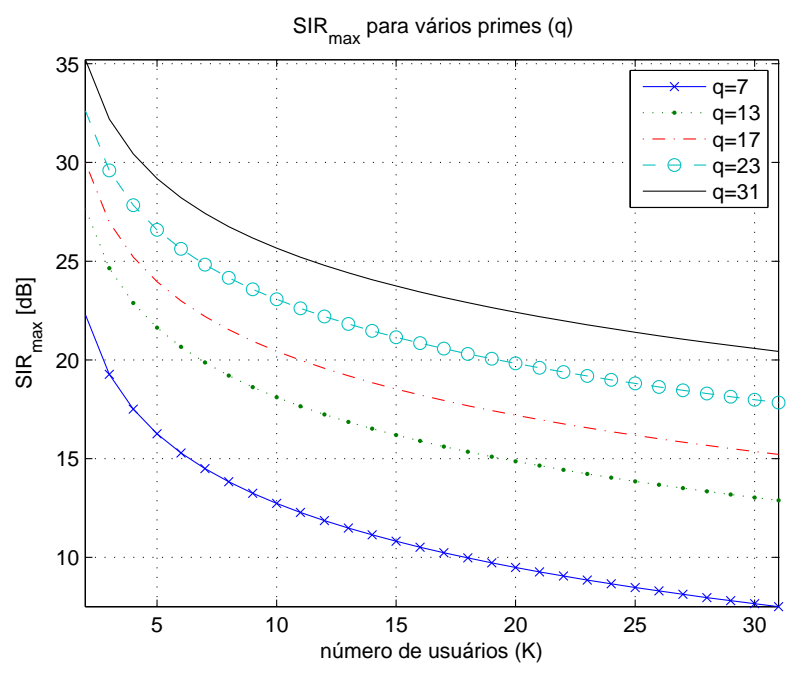

Fig. 2. $S I R_{\max }$ para uma rede estrela para vários $q$.

sistema de telefonia celular. Utilizando (14), a máxima $S I R$ alcançável é

$$
S I R_{\max } \simeq \frac{q^{2} \Gamma_{\max }}{\sigma_{C C}^{2}}=\frac{q^{2}}{(K-1) \sigma_{C C}^{2}}
$$

Essa equação corresponde ao caso de usuários com potências iguais em (5). A Fig. 2 demonstra a variação da $S I R_{\max }$ de acordo com o tamanho da rede para diferentes valores de $q$ (Prime Codes). Assumindo-se $S I R_{\max }=20 \mathrm{~dB}$, e analisando o gráfico, pode-se afirmar que para $q=13$ a rede suporta no máximo 05 usuários do total de 13 usuários, enquanto que para $q=31$ a rede suporta todos os 31 usuários. Na rede óptica estrela da Fig. 1, a $S I R$ para o $i$-ésimo usuário relaciona-se à matriz de atenuação da fibra por:

$$
S I R_{i}=\frac{q^{2} G_{i i} P_{i}}{\sigma_{C C}^{2} \sum_{j=1, j \neq i}^{K} G_{i j} P_{j}+N_{i}}
$$

Desta forma, (16) pode ser utilizada em (6) para calcular a probabilidade de erro de bit da rede óptica CDMA estrela admitindo o emprego de seqüências do tipo Prime Codes, com ou sem controle de potência.

\section{Controle de PotênCia Óptico Particionado}

A avaliação da potência ótima pode ser simplificada pelo particionamento da rede estrela em, Fig. 3:

a) rede de acesso, incluindo o acoplador estrela,

b) rede de broadcasting, situada após do acoplador estrela. Assumindo que $g_{j}=a_{\text {estrela }} \exp \left(-\alpha L_{j}^{\mathrm{tx}}\right)$ é a atenuação do nó transmissor mais perda do acoplador estrela e que $\hat{g}_{i}=$ $\exp \left(-\alpha L_{i}^{\mathrm{rx}}\right)$ é a atenuação da fibra do nó receptor, a CIR no $i$-ésimo receptor é dada por:

$$
\Gamma_{i}=\frac{P_{i} g_{i} \hat{g}_{i}}{\sum_{j=1}^{K} P_{j} g_{j} \hat{g}_{i}-P_{i} g_{i} \hat{g}_{i}+N_{i}} \geq \Gamma^{*}
$$




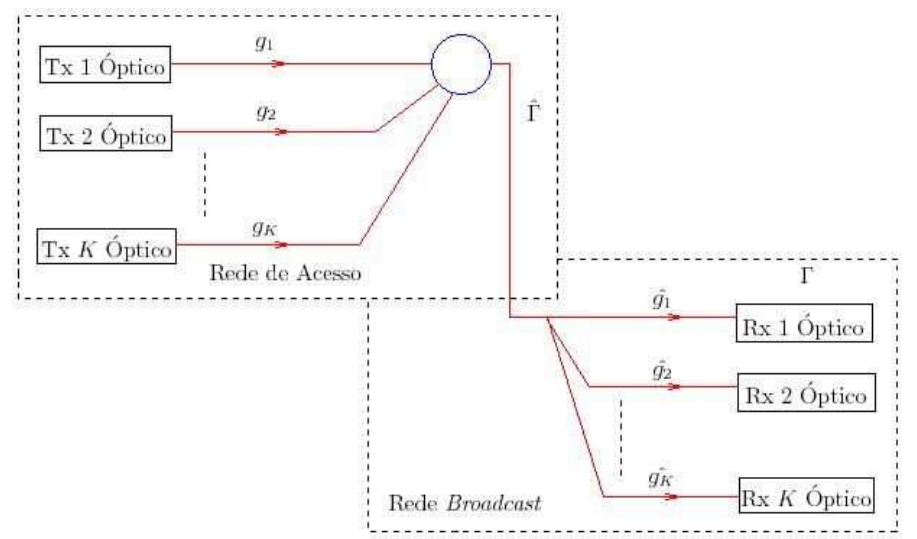

Fig. 3. Particionamento da Topologia Estrela em Rede de Acesso e Rede Broadcast.

com $G_{i j}=g_{j} \hat{g}_{i}$. Neste caso, os elementos da matriz interferência são dados por:

$$
H_{i j}=\left\{\begin{array}{rr}
0, & i=j \\
\frac{g_{j}}{g_{i}}, & i \neq j
\end{array}\right.
$$

Verifica-se que os cabos de fibra após o acoplador estrela não afetam a MAI encontradas pelos nós receptores [5].

Para a rede particionada da Fig. 3, pode-se definir dois valores de CIR: $\Gamma_{i}$ nos nós receptores e $\hat{\Gamma}_{i}$ na saída do acoplador estrela. Assim tem-se,

$$
\begin{aligned}
\Gamma_{i} & =\frac{P_{i} g_{i}}{\sum_{j=1}^{K} P_{j} g_{j}-P_{i} g_{i}+\frac{N_{i}}{g_{i}}}, \\
\hat{\Gamma_{i}} & =\frac{P_{i} g_{i}}{\sum_{j=1}^{K} P_{j} g_{j}-P_{i} g_{i}}
\end{aligned}
$$

onde foi desprezado o ruído de fundo na segunda expressão. Adicionalmente, pode-se admitir $\Gamma_{i} \simeq \hat{\Gamma}_{i}$ se:

$$
\frac{N_{i}}{\hat{g}_{i}} \ll \sum_{j=1}^{K} P_{j} g_{j}-P_{i} g_{i}
$$

Portanto, em redes ópticas CDMA do tipo estrela com MAI limitada, a CIR necessária em cada nó receptor será a mesma daquela encontrada à saída do acoplador estrela: as fibras conectadas após o acoplador estrela não exercem efeito sobre o balanço das potências ótimas. Neste caso, a solução do problema do controle de potência é o autovetor correspondente ao maior autovalor associado à decomposição da matriz $\mathbf{H}$.

Então cada usuário pode avaliar a potência do laser óptico aplicado baseado em uma lookup table com os comprimentos das fibras de outros usuários e o status de cada usuário, se está ON ou OFF. A lookup table é atualizada regularmente e cada vez que o status de um usuário é modificado, o nível de potência ótimo é recalculado.

Empregando-se potências ótimas de laser, para uma dada taxa de erro de bit obtém-se o incremento na capacidade da rede (número de usuários) em comparação ao caso onde não se utiliza nenhum tipo de controle de potência.

\section{Controle de Potência Óptico via Modelo de VERHULST}

Neste trabalho propõe-se adaptar o modelo de Verhulst, anteriormente empregado na solução do problema de controle de potência em sistemas de comunicação sem fio [11], [12], para o cenário das comunicações CDMA ópticas com configuração estrela. O modelo de Verhulst é um modelo de crescimento populacional que descreve a evolução do número de indivíduos de uma determinada espécie biológica, com o passar do tempo, em um ambiente com limitações de alimento e espaço físico. Isto faz com que a população cresça até um tamanho limitado. O modelo dinâmico atribuído à Verhulst [13] é,

$$
\dot{p}=z(p)=p\left(1-\frac{p}{p^{*}}\right)
$$

Integrando-se analiticamente a equação (21) obtém-se,

$$
p(t)=\frac{\exp (t) p(0) p^{*}}{p^{*}+p(0)[\exp (t)-1]}
$$

cujo comportamento assintótico é,

$$
\lim _{t \rightarrow+\infty} p(t)=p^{*}
$$

para qualquer condição inicial $\mathrm{p}(0)$ estritamente positiva, conforme Fig. 4, onde pode-se verificar que quando $p(0)$ for maior que $p^{*}$ (o sinal de $d p / d t$ será negativo), $p(t)$ irá diminuir conforme $p(+\infty)=p^{*}$. Para o sinal $d p / d t$ positivo, $p(t)$ aumentará até que $p(+\infty)=p^{*}[11]$.

A versão discreta implementável para o modelo populacional de Verhulst, em termos da atualização das potências dos $K$ usuários em uma rede de múltiplo acesso, é descrita por [11], [12]:

$p_{i}(n+1)=(1+\alpha) p_{i}(n)-\alpha\left[\frac{\Gamma_{i}(n)}{\Gamma_{i}^{*}}\right] p_{i}(n), i=1, \ldots, K$.

sendo $0<\alpha \leq 1$ o fator responsável pela velocidade de convergência (valores de $\alpha$ próximo de 1 indicam convergência rápida) e simultaneamente determina a qualidade da solução (após a convergência) em termos de erro quadrático médio em relação a $p_{i}^{*}$.

Tal procedimento até o equilíbrio das potências caracteriza o problema do controle de potência distribuído baseado na equação de Verhulst.

Em [12] foram discutidas onze proposições para provar a convergência do algoritmo do controle de potência distribuído de Verhulst (DPCA-V).

\section{Resultados de Simulação}

As simulações foram feitas em ambiente MatLab, utilizando os parâmetros de sistema OCDMA estrela indicados na Tabela I. Inicialmente, a potência ótima dos lasers para o problema do controle de potência particionado foi obtida para cada um dos $K$ usuários via inversão de matriz, obtendo-se o vetor $\mathbf{P}^{*}$ através da equação (13). A Fig. 5 exemplifica uma situação típica para $K=31$ usuários, e a Fig. 6 apresenta a evolução das potências alocadas para os 31 nós (linhas cheias) segundo a aplicação decorrente da equação (24), considerando $n=$ $1,2,3, \ldots, 800$ iterações. $\mathrm{O}$ sistema analisado considera uma 


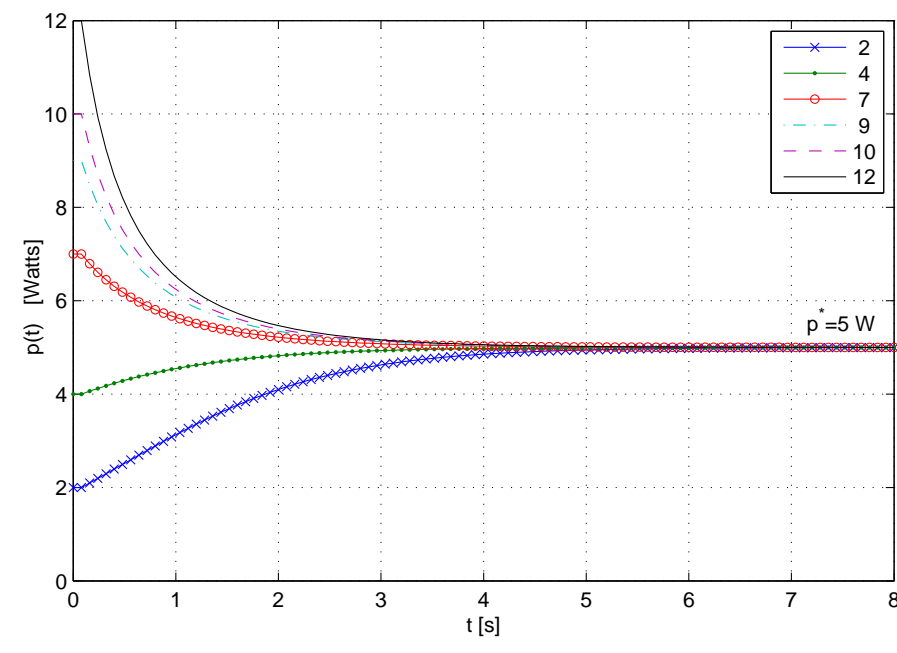

Fig. 4. Curvas $p(t)$ parametrizadas por diferentes condições iniciais $p(0)$.

rede com nós distribuídos uniformemente distantes entre 2 e $50 \mathrm{~km}$ do acoplador estrela, máxima potência do laser de 20 dBm para cada nó; desprezou-se o efeito da dispersão e nãolinearidade da fibra. Observa-se que para valores reduzidos do fator de convergência, $\alpha=0,1$ na Figura 6.a, são necessárias de 600 a 800 iterações para o algoritmo atingir os respectivos valores das potências ótimas obtidos via (13), indicados pelas linhas pontilhadas na figura. $\grave{A}$ medida que $\alpha \rightarrow 1$, o algorithmo de controle de potência de Verhulst converge mais rapidamente para o vetor de potência ótimo às custas de uma redução na qualidade da solução [12], necessitando porém um menor número de iterações, conforme indicado na Fig. 6.b.

TABELA I

PARÂMETROS DE SIMULAÇÃO DO SiSTEMA OCDMA ESTRELA

\begin{tabular}{ll}
\multicolumn{2}{c}{ PARTICIONADO } \\
\hline Parâmetro & \multicolumn{1}{c}{ Valores Adotados } \\
\hline \hline \multicolumn{2}{c}{ Sistema OCDMA } \\
\hline Seq. Espalham. Prime, q & 31 \\
$\sigma_{C C}^{2}$ & 0,29 \\
Taxa de dados & $2,5 \mathrm{~Gb} / \mathrm{s}$ \\
Pot. laser disponível & $P_{\max }=20 \mathrm{dBm}$ \\
& $P_{\min }=0,01 P_{\max }$ \\
\# us. Tx & 31 \\
\# us. Rx & 31 \\
Distância Tx-Acoplador & $\sim \mathcal{U}[2,50] \mathrm{Km}$ \\
\hline \multicolumn{2}{c}{ Fibra Optica } \\
\hline Comprimento de Onda & $1550 \mathrm{~nm}$ \\
$\gamma$ & $0,2 \mathrm{~dB}$ \\
$a$ & $0,2 \mathrm{~dB} / \mathrm{km}$ \\
\hline \multicolumn{2}{c}{ DPCA Verhulst } \\
Tipo & distribuído \\
$\alpha$ & faixa $[0,10 ; 0,99]$ \\
\hline
\end{tabular}

Assim, pôde-se verificar que com o controle de potência os nós mais distantes (usuários: 2, 4, 8, 14, 15, 28, por exemplo) recebem mais potência do que os nós mais próximos ao acoplador estrela (usuários: 3, 13, 17, 19, 24, 31, por exemplo), ao invés de todos receberem a mesma potência, o que causaria uma grande quantidade de MAI no receptor, diminuindo assim a capacidade do sistema.

As potências obtidas a cada iteração via modelo de Verhulst, na Fig. 6, foram comparadas com a solução da potência ótima
$\left(\mathbf{P}^{*}\right)$, obtida analiticamente em (13). Nota-se que independentemente da potência inicial atribuída a cada laser, assumida uma variável aleatória uniformemente distribuída no intervalo $\left[P_{\min } ; P_{\max }\right]$, a aplicação da equação (24) permite obter a convergência das potências dos lasers para as respectivas potências ótimas após um determinado número de iterações, função do parâmetro $\alpha$. À medida que $\alpha(0<\alpha \leq 1)$ cresce, a velocidade de convergência é melhorada. No entanto, a qualidade da solução, isto é, o erro quadrático normalizado em relação à potência ótima analítica, $P^{*}$, tende a aumentar [12].

Para efeito de comparação, a Fig. 5.c indica a faixa dinâmica, em dB, para a matriz de interferência normalizada H, correspondente à configuração do sistema. Na configuração adotada, cujas distâncias entre os lasers Tx e o acoplador estrela assumem valores uniformente distribuídos entre $2 \mathrm{Km}$ e $50 \mathrm{Km}$, a matriz $\mathbf{H}$ resulta em valores na faixa de aproximadamente $\pm 5 \mathrm{~dB}$. Por fim, a Fig. 5.b indica as correspondentes distâncias entre receptor e acoplador; conforme discutido anteriormente, após o acoplador estrela, não há ocorrência de interferência de múltiplo acesso (MAI), não contribuindo, portanto, para o balanço de potência dos lasers transmissores, conforme já mostrado no decorrer do trabalho.
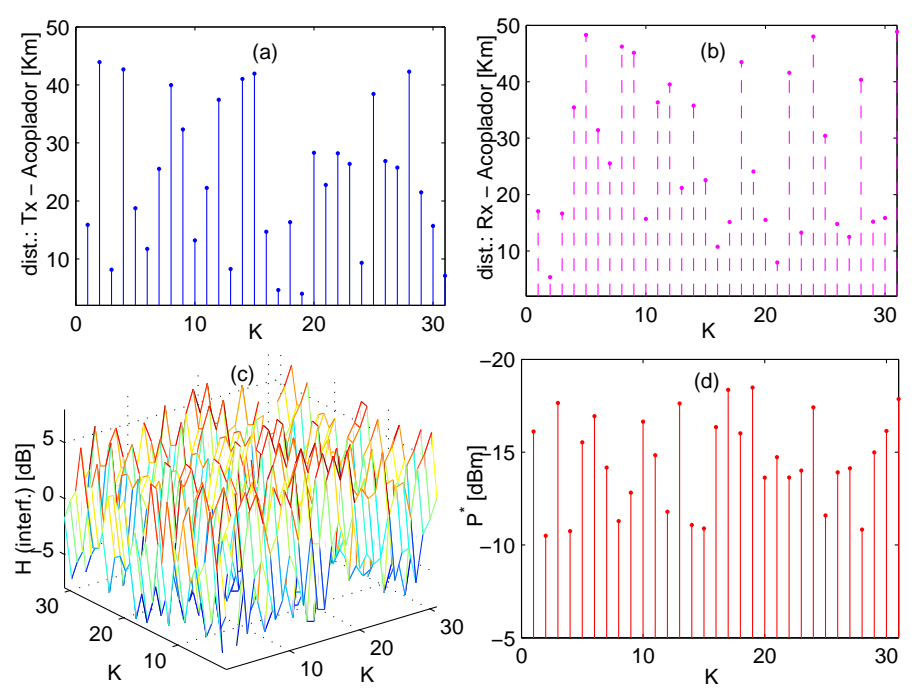

Fig. 5. Comprimento das fibras dos nós a) transmissores e b) receptores até o acoplador estrela, c) matriz interferência $\mathbf{H}$ e d) potência ótima dos lasers com controle de potência particionado via $\mathbf{P}^{*}$, eq. (13).

\section{CONCLUSÕES}

Neste trabalho foi proposto o controle de potência óptico distribuído utilizando o modelo de Verhulst para redes OCDMA estrela particionado, comparado a qualidade das soluções encontradas com aquelas obtidas analiticamente via inversão da matriz de interferência. $\mathrm{O}$ controle de potência centralizado necessita de um nó central com informação sobre o ganho de todos os links. Já no controle de potência particionado cada usuário poderia ser equipado com a informação do status dos outros nós, permitindo a distribuição de potência apropriada para suportar o balanceamento de potência. Uma vez que as fibras após o acoplador estrela (nós receptores) não 

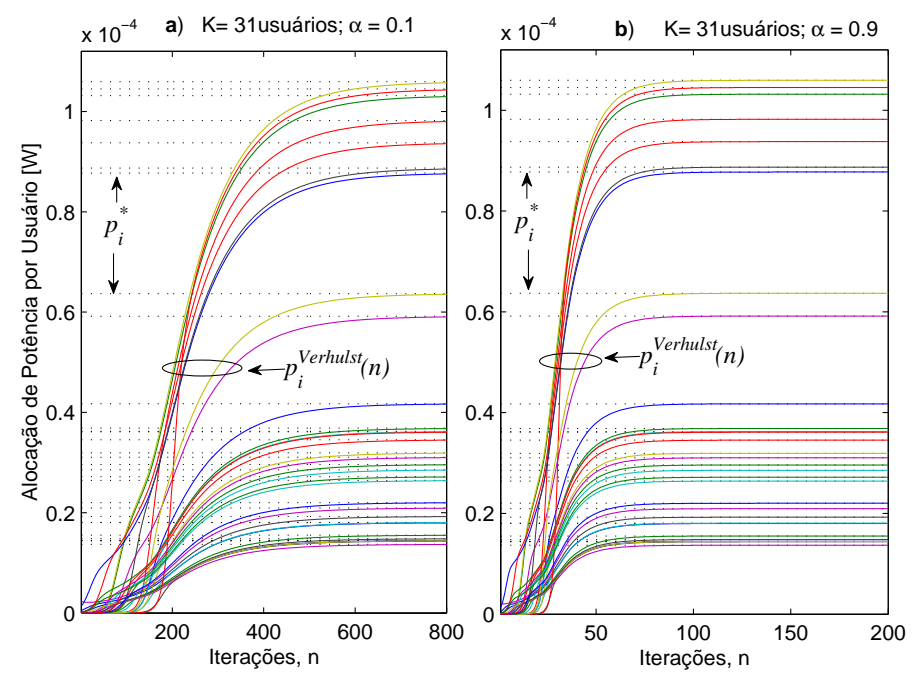

Fig. 6. Curvas da convergência da potência inicial de cada laser para sua respectiva potência ótima: $p_{i}(n \rightarrow \infty)=p_{i}^{*}, i=1,2, \ldots, 31$. a) $\alpha=0,1$; b) $\alpha=0,9$.

influenciam no cálculo do controle de potência (a CIR encontrada na saída do acoplador estrela é praticamente a mesma encontrada nos nós receptores), pôde-se utilizar somente os parâmetros dos transmissores da fibra e do acoplador estrela. A qualidade da solução para o problema do controle de potência proporcionada pelo DPCA de Verhulst é similar ao obtido via inversão da matriz interferência, mesmo quando há erros nas estimativas dos ganhos de canal óptico (atenuação, efeitos de dispersão, perdas no acoplador etc). Assim, um controle de potência distribuído, onde cada nó recebe a quantidade de potência determinada para o funcionamento do sistema, é capaz de proporcionar um relativo aumento da capacidade do sistema devido à diminuição da MAI proporcionada pelo adequado balanço de potência dos lasers.

\section{AgRAdECIMENTOS}

À CAPES pela bolsa de estudos de mestrado e à Universidade Estadual de Londrina pela infraestrutura.

\section{REFERÊNCIAS}

[1] R. Ramaswami and K. N. Sivarajan, Optical networks, a practical perspective. Morgan Kaufmann publishers, 1998.

[2] A. Stok and E. H. Sargent, "Lighting the local area: Optical codedivision multiple-access and quality of service provisioning," IEEE Network, vol. 14, no. 6, p. 42, Nov./Dec. 2000.

[3] H. Yashima and T. Kobayashi, "Ocdma with time-hopping and power control for multimedia networks," Journal of Lightwave Tech., vol. 21, no. 3, p. 695, March 2003.

[4] M. S. E. Naser G. Tarhuni and T. O. Korhonen, "Nonlinear power control for asynchronous fiber-optic cdma networks," in IEEE ICC 2006, June 2006, pp. 2782-2786.

[5] N. G. Tarhuni, M. S. Elmusrati, T. O. Korhonen, and E. Mutafungwa, "Multi-access-interference mitigation using power control in opticalcdma star network," in IEEE International Conference on Communications, ICC'05, vol. 3, May 2005, pp. 1593-1597.

[6] J. F. H. Chao-Chin Yang and T.-C. Hsu, "Differentiated service provision in optical cdma network using power control," IEEE Photonics Technology Letters, vol. 20, no. 20, pp. 1664-1666, October 2008.

[7] W. Kwong, P. Prucnal, and P. Perrier, "Synchronous versus asynchronous cdma for fiber-optic lans using optical signal processing," in Global Telecommunications Conference GLOBECOM 89, vol. 2, Nov. 1989, pp. 1012-1016.
[8] P. R. Prucnal, M. A. Santoro, and T. R. Fan, "Spread spectrum fiberoptic local area network using optical processing," Journal of Lightwave Technology, vol. 4, pp. 547-554, May 1986.

[9] G. C. Yang and W. Kwong, "Performance analysis of optical cdma with prime codes," Electronics Letters, vol. 31, pp. 569-570, March 1995.

[10] M. S. Elmusrati, "Power control and mimo beamforming in cdma mobile communication systems," Helsink University of Technology, Report 129, August 2002.

[11] T. J. Gross and P. J. E. J. Taufik Abrao, "Distributed power control algorithm for multiple access systems based on verhulst model," Feb. 2009, submission process.

[12] T. J. Gross, T. Abrão, and P. J. E. Jeszensky, "Algoritmo de controle de potência distribuído fundamentado no modelo populacional de verhulst," Revista da Sociedade Brasileira de Telecomunicações, vol. 20, no. 2, pp. 59-74, 2006.

[13] P. F. Verhulst, "Notice sur la loi que la population poursuit dans son accroissement," Correspondance mathématique et physique, pp. 10:113121, 1838. 